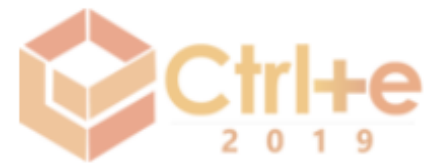

IV Congresso sobre Tecnologias na Educação (Ctrl+E 2019)

Recife, Pernambuco - Brasil

28 a 30 de agosto de 2019

\title{
Um Jogo para Dispositivos Móveis com o Objetivo de Auxiliar a Aprendizagem de Libras, ELiS e Português
}

\author{
Igor Victor Lucena do Nascimento1, Taciana Pontual Falcão1
}
1Departamento de Computação, Universidade Federal Rural de Pernambuco (UFRPE), Rua Dom Manoel de Medeiros, s/n, Dois Irmãos, Recife - PE - Brazil
igorvlnascimento@gmail.com, taciana.pontual@ufrpe.br

\begin{abstract}
There are millions of hearing-impaired people in Brazil, and, most of them have some difficulty to communicate in Portuguese, which leads to exclusion from society in many aspects. The language mostly used by the Deaf in Brazil is Libras (Brazilian Sign Language) which is expressed through gestures and facial expressions. This language has its own writing through symbols, one of them being called ELiS, or written sign language, which assists in the process of literacy of deaf children in Portuguese. This work presents a casual game for mobile devices, developed with Unity platform, with the purpose of helping deaf children in literacy and acquisition of Libras, ELiS and Portuguese.
\end{abstract}

Resumo. Existem milhões de pessoas com alguma deficiência auditiva no Brasil, e a maioria destes individuos, têm alguma dificuldade de comunicar-se por meio da Língua Portuguesa e, consequentemente, com a sociedade. A língua mais usada pelos Surdos no Brasil é a Libras (Lingua Brasileira de Sinais) que se expressa por meio de gestos e expressões faciais. Essa língua tem a sua própria escrita, uma delas é o ELiS, ou Escrita de Língua de Sinais, que auxilia no processo de alfabetização das crianças surdas em Português. Diante disso, o presente artigo é sobre a criação de um jogo de memória para dispositivos móveis, desenvolvido por meio da plataforma Unity, que auxilie as crianças surdas na alfabetização e aquisição da Libras, ELiS e Português.

\section{Introdução}

A comunicação é uma ferramenta primordial nas relações humanas para troca de experiências com o mundo exterior. A forma mais utilizada de comunicação para se transmitir o conhecimento e a experiência entre as pessoas se dá através da língua falada e escrita. Um estudo divulgado pela Organização Mundial de Saúde [ORGANIZAÇÃO MUNDIAL DA SAÚDE, 2011] revela que quase 1 bilhão de pessoas no mundo $(15,3 \%$ da população mundial) têm alguma deficiência grave ou moderada, seja ela auditiva, visual ou física. De acordo com o mesmo estudo, uma em cada cinco dessas pessoas tem sua vida dificultada por causa da deficiência. De acordo com o Censo de 2010 do Brasil [IBGE, 2010], existem 7,6 milhões de pessoas que apresentam alguma dificuldade auditiva, somados os 2,1 milhões que são Surdos ou pessoas com 
deficiência auditiva. No total, 9,7 milhões de pessoas no Brasil têm alguma deficiência auditiva, a maior parte delas entre os 15 e 64 anos de idade. Essas pessoas apresentam alguma dificuldade ou mesmo não conseguem se comunicar eficientemente com grande parte da sociedade que não tem o conhecimento da Libras (Língua Brasileira de Sinais). E é necessário, na maioria das vezes, possuir o domínio da Língua Portuguesa escrita e/ou falada para inserção das pessoas nas universidades e em algumas áreas do mercado de trabalho. A Libras é a língua utilizada pelos Surdos e que boa parte da sociedade não compreende devido à sua natureza visual-espacial ou gesto-visual. De acordo com o mesmo censo citado acima [IBGE, 2010], 61,1\% da população que tem pelo menos uma deficiência (seja ela auditiva, visual entre outras) não possui instrução e não tem o ensino fundamental completo, contra $38,2 \%$ para aqueles que não possuem nenhuma deficiência. Esses dados mostram a carência da alfabetização dos Surdos nas escolas. E, cada dia mais, com o avanço da tecnologia, o mercado torna-se mais exigente de uma maior qualificação [PEREIRA, 2011].

As Diretrizes Nacionais para a Educação Especial na Educação Básica, Resolução do Conselho Nacional de Educação e o Conselho de Educação Básica $\mathrm{n}^{\circ} 2 / 2001$, no artigo 2, dizem que os "sistemas de ensino devem matricular todos os alunos, mesmo aqueles com necessidades especiais e cabe às escolas proporcionar o atendimento diferenciado aos diversos educandos, sejam eles com necessidades especiais ou não, assegurando uma educação de qualidade para todos" [CONSELHO NACIONAL DE EDUCAÇÃO, 2001]. Pela Lei 10.436 do Brasil, a Libras é reconhecida como língua oficial brasileira e os surdos têm o direito a aulas ministradas por meio dela ou com a presença de um intérprete [BRASIL, 2002]. Este artigo apresenta a criação de uma aplicação móvel de jogo de memória que auxilie a alfabetização das crianças surdas em Língua Portuguesa, Libras e ELiS (escrita de língua de sinais).

\section{A Comunicação dos Surdos}

\subsection{Libras}

Libras é a sigla para Língua Brasileira de Sinais e é a linguagem adotada para a comunicação com os surdos. Durante muito tempo se pensou que a língua de sinais era mera mímica, porém pesquisas mostram que a Libras apresenta uma complexidade e expressa ideias abstratas assim como qualquer língua oral. Não só a Libras, mas qualquer outra língua gestual possui vocabulários e regras específicas não derivados das línguas orais. Cada país tem a sua própria língua de sinais [SILVA, 2012]. O linguista americano, chamado Stokoe foi pioneiro no estudo da fonologia, morfologia e sintaxe da American Sign Language (ASL), língua de sinais utilizada pelos surdos nos Estados Unidos da América. É muito importante manter o contato das crianças surdas, desde cedo, com a língua de sinais própria de seus respectivos países. Pois, de acordo com uma pesquisa nos Estados Unidos (EUA), 90\% das crianças surdas possuem pais ouvintes que não conhecem a língua de sinais, que, no caso dos EUA, chama-se ASL. As crianças só chegam a aprender a língua mais tarde e "são raramente expostas ao ASL como primeira língua de sinais" [SCHICK, 2005, p. 219, tradução nossa]. Isso não é bom para a criança pois a infância é um período crítico de aquisição linguística. Quanto mais cedo essas crianças tiverem o contato com a língua de sinais, mais cedo ficarão proficientes e poderão aprender a língua dos ouvintes. 


\subsection{ELiS}

ELiS é a sigla para Escrita de Língua de Sinais criado por Mariângela Estelita Barros, no ano de conclusão do seu mestrado pela Universidade Federal de Goiás (UFG), e finalizado no seu doutorado [BARROS, 2015]. "A ELiS é um sistema de escrita alfabético e linear, cujos caracteres, denominados visografemas, foram desenvolvidos especialmente para ela. Os visografemas representam os elementos visuais que compõem a língua de sinais" [BARROS, 2015]. Existem outras escritas de línguas de sinais, tais como o SignWriting (SW), que é bastante utilizado por outros países. A escolha da escrita ELiS para o presente artigo se deu por conta da simplicidade, praticidade e organização da estrutura da $E L i S$, além de ser uma escrita em potencial também para uso de outras linguagens de sinais além da Libras [CARVALHO et al., 2016]. Existem, também, cada vez mais trabalhos de pesquisa visando apresentar a eficácia e praticidade dessa escrita, bem como a difusão da literatura por meio da ELiS para o aproveitamento dos surdos [CARVALHO et al., 2016; BENASSI; DUARTE; PADILHA, 2015].

\subsection{Trabalhos relacionados}

Existe um trabalho que aborda o SignWriting (SW) do ASL [KHENISSI et al., 2015] através de um jogo de memória online para aumentar o vocabulário inglês dos surdos fazendo correspondência das palavras em inglês e o SW correspondente. Nesse jogo é necessário um conhecimento prévio em SignWriting, o que dificulta o usuário atingir o objetivo do jogo. Por isso, a aplicação do artigo proposto possui uma pedagogia que leva o usuário a aprender primeiro a Libras de cada animal para, depois, aprender o ELiS referente à Libras e, por fim, o Português. Existem alguns aplicativos móveis para ensinar ASL a crianças. Um deles é o SiGame que é um jogo de memória para o aprendizado de ASL ou em Linguagem de Sinais Alemã. No jogo, quando um cartão é clicado, ele é mostrado um avatar fazendo um sinal, contendo embaixo a palavra em inglês correspondente ao sinal. A criança deve achar as correspondências de sinais iguais [GMBH, 2015]. Existem outros jogos voltados para as crianças surdas para auxiliá-las no aprendizado de sua língua de sinais de seu próprio país tais como o Sign My World para crianças surdas da Austrália [KORTE; POTTER; NIELSEN, 2012]. De jogos brasileiros existem o Librário e o Librazuka que ensinam a Libras. Porém, o Librário é um jogo da memória em Libras cujos cartões não mostram os gestos em Libras, mas apenas a imagem. Só é mostrado um vídeo em Libras de uma pessoa fazendo o gesto caso a pessoa clique num botão específico para mostrar esse vídeo. $\mathrm{O}$ Librazuka não possui animação como o Librário, que foi desenvolvido em Unity também, e não é tão intuitivo para as crianças surdas. Pois apresenta os módulos de jogos com os títulos em português. Muitas crianças surdas não entendem o português e podem não saber onde clicar para jogar.

\section{Desenvolvimento}

O jogo apresentado a seguir é uma evolução de trabalho anterior. Inicialmente, a ideia foi comparar a abordagem tradicional de ensino nas escolas que usam jogos de memória feitos de papel, aplicando-se o jogo na escola. Buscaram-se imagens em Libras com desenho estático do sinal e a sua correspondência na imagem. Por exemplo, a imagem em Libras significando a palavra "leão" teria correspondência com o desenho do leão e seu nome abaixo do desenho. O jogo aqui apresentado foi desenvolvido na plataforma Unity, uma plataforma muito usada para criação de jogos. A escolha da plataforma 
Unity se deu por ela ser uma ferramenta muito poderosa para se fazer jogos e por ser multiplataforma, podendo ser construída para várias plataformas diferentes, tais como: Android, iOS, Windows, entre outros [UNITY, 2019]. As categorias posteriores são habilitadas à medida que a criança vai passando os níveis para que elas passem por todas as etapas do aprendizado até chegar a última categoria que é: Imagem Português, como mostra a Figura 1. Essa é uma forma bilíngue de alfabetizar as crianças começando pela sua língua materna (Libras) e uma forma de direcionar a criança ao aprendizado em etapas, evitando que ela comece pela categoria mais difícil e, assim, o aplicativo fique desagradável e ela perca a motivação.

Ao clicar no primeiro nível da categoria da Imagem - Libras, a criança é direcionada para o jogo que possui 4 subníveis. Cada subnível aumenta a dificuldade pois aumenta o número de cartas no jogo que vai de 4 até 10 cartas, primeiro e quarto subníveis, respectivamente. Cada nível funciona da mesma forma, porém com animais diferentes. No jogo é preciso encontrar a correspondência entre a imagem do animal e seu sinal em Libras, ou da sua escrita em EliS, ou da sua palavra em português. Em cada jogo, o usuário possui 5 (cinco) vidas representadas pelo ícone da aplicação no canto superior esquerdo da tela do jogo como mostra a Figura 2.

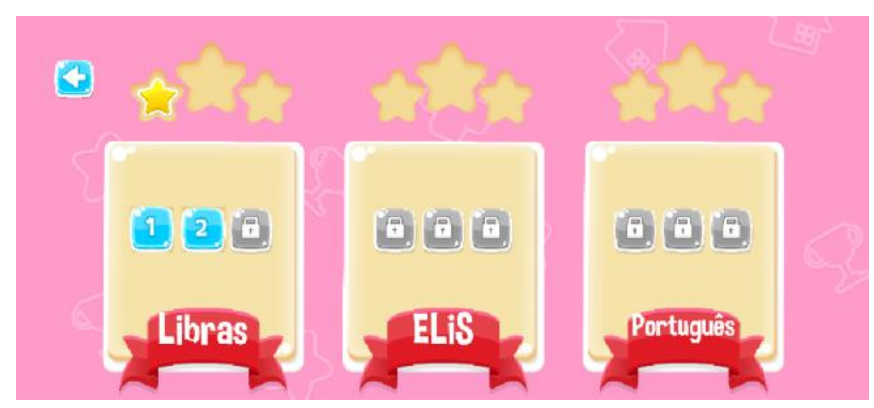

Figura 1. Menu do jogo com apenas os níveis 1 e 2 da categoria Imagem Libras habilitados

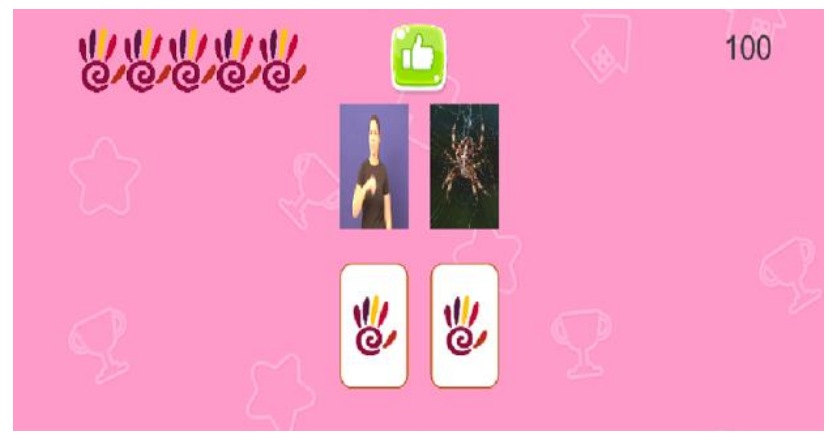

Figura 2. Layout do jogo com 4 cartas

O jogador começa com 0 pontos. Quando o jogador clica em um cartão, este automaticamente vai para o meio da tela e é girado automaticamente a fim de que o jogador visualize melhor o que está no cartão. Quando acerta uma correspondência, ganha mais 100 pontos, o dispositivo móvel vibra por um momento e é mostrado um ícone de um sinal com polegar de cor verde como uma sinalização e um feedback sensorial e visual, respectivamente, que o usuário acertou. Caso contrário, se o jogador errar, perde 50 pontos, o dispositivo vibra por mais um momento e é mostrado um ícone de um sinal com polegar de cor vermelha como um feedback sensorial e visual, 
respectivamente, indicando que o usuário errou. Dessa forma, as diretrizes 23 e 31 para o desenvolvimento de jogos eletrônicos, que é dar um feedback sonoro e/ou visual às crianças e de apresentar cores vivas e fortes para indicar a principal atividade do jogo, segundo Canteri (2014), estão sendo seguidas.

\subsection{Avaliação do aplicativo}

Como informado anteriormente, o aplicativo é uma melhoria de uma versão antiga que tinha sido testada com as crianças surdas em uma escola de Recife-PE. Vale ressaltar que a versão antiga da aplicação utilizava SignWriting ao invés da ELiS. Além do teste com as crianças, houve uma entrevista com a professora dos alunos. Antes da avaliação da aplicação, houve um pré-teste para avaliar o conhecimento dos alunos sobre Libras, SignWriting e Português. Posteriormente, aconteceu a avaliação da aplicação do jogo. Por último, teve-se o pós-teste que foi a mesma metodologia do pré-teste com o objetivo de avaliar o conhecimento das crianças após o jogo. As crianças surdas eram da faixa etária de 15 a 16 anos. Alguns tinham mais conhecimento de Libras, outros menos. Nenhuma das crianças tinha conhecimento em SignWriting. Cada uma das crianças vivia em diferentes contextos familiares. Houve 3 mediadores na avaliação do jogo, um mediador que acompanhava as crianças no jogo e os outros dois entregavam o celular e faziam anotações. A avaliação do novo aplicativo, aqui apresentado e desenvolvido com base nas melhorias identificadas nesta primeira avaliação, será feita em escolas municipais de Recife-PE com uma pequena prova como pré-teste e pós-teste. A avaliação da aplicação será da mesma forma que a avaliação da versão antiga. A versão atual é uma melhoria da versão antiga a partir dos resultados obtidos da mesma.

\section{Resultados}

O resultado da avaliação do jogo na versão antiga foi de que as crianças demonstraram interesse, motivação e engajamento no jogo. Esses resultados foram muito importantes para melhorias feitas no trabalho atual. As crianças mais adiantadas da turma ficaram um pouco dispersas. A tendência das crianças era a colaboração. Nenhuma delas pediu para parar o jogo antes do final e todas gostaram do jogo. Havia um aluno com paralisia cerebral na turma que teve bastante dificuldade de tocar nos cartões. Alguns cartões estavam muito pequenos e difíceis de serem vistos. Essa dificuldade fez com que o autor melhorasse a aplicação fazendo com que ao clicar nos cartões, eles aumentassem de tamanho e fossem para o meio da tela.

No pré-teste, todas as crianças acertaram Libras, e poucas acertaram o Português. Não foi feito o teste para o Sign Writing pois a professora disse que nenhum deles conhecia. Depois do jogo, todos continuaram acertando Libras. Dessa vez foi testado o Sign Writing para ver se as crianças aprenderam e muitas acertaram mais da metade ou a metade, principalmente dos símbolos que mais pareciam com o sinal em Libras. O pós-teste com o Português não foi muito satisfatório. As crianças tiveram dificuldade de visualizar os sinais por conta do tamanho dos smartphones. Elas também queriam uma resposta rápida do jogo, clicando rapidamente e sobrecarregando a aplicação. Na nova versão do jogo de que trata este artigo, quando clica-se em um cartão, todos os outros são desabilitados, forçando a criança esperar que o próximo cartão esteja disponível para clicar, evitando, assim, sobrecarregar a aplicação. Assim como, também, foram incluídas mais imagens de animais no jogo para que possam aprender mais. Serão utilizados mais módulos no jogo, tais como: números, letras, objetos, entre outros. Isso será colocado como trabalho futuro. Na versão antiga tinha o 
módulo de flashcards em que um cartão tinha de um lado o sinal de Libras e do outro a foto do animal correspondente. Esse módulo foi excluído pois na avaliação da versão antiga, as crianças estavam mais atentas ao jogo em si do que aos flashcards.

\section{Considerações finais}

Acredita-se que este trabalho apresenta um potencial significativo no ensinoaprendizagem das crianças surdas por meio das tecnologias educacionais, proporcionando uma melhor qualidade da educação dessas pessoas que possuem necessidades especiais. $\mathrm{O}$ jogo foi feito como melhoria da versão anterior de acordo com os resultados e sugestões obtidos.

\section{Referências}

ORGANIZAÇÃO MUNDIAL DE SAÚDE. Relatório Mundial de Saúde 2011. Disponível

em: $<$ http://apps.who.int/iris/bitstream/10665/70670/9/WHO_NMH_VIP_11.01_por.pdf >. Acesso em: 24 de setembro de 2015

IBGE. Tabelas - Pessoas com Deficiência. Censo Demográfico 2010. Disponível em:

$<\mathrm{ftp}$ //ftp.ibge.gov.br/Censos/Censo_Demografico_2010/Caracteristicas_Gerais_Reli giao_Deficiencia/tab1_3.pdf $>$.

BRASIL. Decreto n. 5.625, de 22 de setembro de 2005. Regulamenta a Lei $\mathrm{n}^{0} 10.436$, que dispõe sobre a Língua Brasileira de Sinais - Libras, e o art. 18 da Lei ${ }^{\circ} 10.098$, de 19 de dezembro de 2000. Disponível em: $<$ https://www.planalto.gov.br/ccivil_03/_Ato2004-2006/2005/Decreto/D5626.htm> Acesso em: 21 de maio de 2015.

PEREIRA, Ana Maria. Tecnologia X Educação. 2011. 44 f. Monografia (Especialização) - Curso de Docência do Ensino Superior, Universidade Candido Mendes, Rio de Janeiro, 2011.

CONSELHO NACIONAL DE EDUCAÇÃO. Câmara de Educação Básica. Resolução CNE/CEB 2/2001. Diário Oficial da União, Brasília, 14 de setembro de 2001. Seção 1E, p. 39-40.

BRASIL. Lei $\mathrm{N}^{o}$ 10.436, de 24 de abril de 2002. Dispõe sobre a Língua Brasileira de Sinais - Libras e dá outras providências. Brasília, 2002.

KORTE, Jessica; POTTER, Leigh Ellen; NIELSEN, Sue. Designing a Mobile Video Game to Help Young Deaf Children Learn Auslan. British Computer Society Swinton. Birmingham, p. 345-350. 10 set. 2012.

SILVA, Rafaela Cota da. SignWriting: um sistema de escrita das línguas gestuais. Aplicação à Língua Gestual Portuguesa.. 2012. 12 f. TCC (Graduação) - Curso de Língua Gestual Portuguesa, Escola Superior de Educação de Coimbra, Coimbra, 2012.

BARROS, Mariângela Estelita. ELiS: sistema brasileiro de escrita das línguas de sinais. Porto Alegre: Penso, 2015.

CARVALHO, Andréa dos Guimarães de et al. Libras e ASL representadas pela Escrita de Línguas de Sinais - ELiS. Revista Intercâmbio dos Congressos Internacionais 
de Humanidades, Brasília, n. 6, p.23-34, jan. 2016. Disponível em: $<$ http://unb.revistaintercambio.net.br/24h/pessoa/temp/?file=anexo, 1,11620,3003,300 3.Libras\%20e \%20ASL \%20representadas\%20pela\%20Escrita\%20das\%20L\%C3\%A Dnguas\%20de\%20Sinais\%20-\%20ELiS>. Acesso em: 30 jun. 2019.

BENASSI, Claudio Alves; DUARTE, Anderson Simão; PADILHA, Simone de Jesus. POIESIS DA LIBRAS E DA ESCRITA DAS LÍNGUAS DE SINAIS (ELiS): A utilização da visualidade da língua e da ELiS na poética de Duarte. Revista Diálogos, Cuiabá, v. 3, n. 2, p.37-47, dez. 2015.

UNITY. Products. 2019.

Disponível

em: $<$ https://unity3d.com/unity?_ga=2.227439646.2050674666.156198851355326164.1555643705>. Acesso em: 01 jul. 2019.

SCHICK, Brenda. The Development of American Sign Language and Manually Coded English Systems. In: MARSCHARK, Marc; SPENCER, Patricia Elizabeth. Oxford Handbooks of Deaf Studies, Language, and Education. New York: Oxford University Press, 2005. Cap. 16. p. 219-222.

KHENISSI, Mohamed Ali et al. A Learning Game for Deaf Learners. 2015 IEEE 15th International Conference On Advanced Learning Technologies. Taiwan, $p$. 418-422. jul. 2015.

GMBH, Sigame. $\quad$ SiGame. $2015 . \quad$ Disponível em: $<$ https://play.google.com/store/apps/details?id=com.sigameapp.SiGame\&hl=pt_BR $>$ . Acesso em: 26 jun. 2016.

CANTERI, Rafael dos Passos. Diretrizes para o Design de Aplicações de Jogos Eletrônicos para Educação Infantil de Surdos. 2014. 39 f. Dissertação (Mestrado) - Curso de Informática, Setor de Ciências Exatas, Universidade Federal do Paraná, Curitiba, 2014. Disponível em: $<$ http://acervodigital.ufpr.br/bitstream/handle/1884/35755/R - D - RAFAEL DOS PASSOS CANTERI.pdf?sequence=1\&isAllowed=y $>$. Acesso em: 26 jun. 2016. 